MITIGATING THE SOCIO-ECONOMIC COSTS OF TRANSPORTATION INFRASTRUCTURE PROJECTS AND ENHANCING COMMUNITY LIVABILITY:

A CASE STUDY OF EGLINTON CROSSTOWN, ST. CLAIR RECONSTRUCTION \& CENTRAL CORRIDOR LRT PROJECTS AND THEIR OUTCOMES.

\author{
by: \\ Danielle Culp \\ Bachelor of Arts (Honours), University of Toronto, 2015 \\ A Major Research Paper \\ presented to Ryerson University \\ in partial fulfillment of the requirements for the degree of \\ Master of Planning \\ in \\ Urban Development
}

Toronto, Ontario, Canada, 2018

(C) Danielle Culp 2018 


\section{Author's Declaration for Electronic Submission of MRP}

I hereby declare that I am the sole author of this MRP. This is a true copy of the MRP, including any required final revisions.

I authorize Ryerson University to lend this MRP to other institutions or individuals for the purpose of scholarly research.

I further authorize Ryerson University to reproduce this MRP by photocopying or by other

means, in total or in part, at the request of other institutions or individuals for the purpose of scholarly research.

I understand that my MRP may be made electronically available to the public. 


\title{
MITIGATING THE SOCIO-ECONOMIC COSTS OF TRANSPORTATION INFRASTRUCTURE PROJECTS AND ENHANCING COMMUNITY LIVABILITY: \\ A CASE STUDY OF EGLINTON CROSSTOWN, ST. CLAIR RECONSTRUCTION \& CENTRAL CORRIDOR LRT PROJECTS AND THEIR OUTCOMES.
}

\author{
(C) Danielle Culp, 2018 \\ Master of Planning \\ in \\ Urban Development \\ Ryerson University
}

\begin{abstract}
This research examines three case studies of transportation projects within the North American context including: the Eglinton Crosstown LRT in Toronto, St. Clair Streetcar reconstruction in Toronto, and the Central Corridor LRT in Minnesota to determine how planners can utilize planning policy and financial policy tools to offer solutions to help mitigate the social costs of transportation infrastructure projects for the affected communities. Results indicate that community benefits agreements and grants can be effective planning policy and financial policy tools that could be used to help mitigate the negative impacts of Light Rail Transit construction. Results also indicate that clear evaluative frameworks must be established, including clear targets, thresholds, reporting, and compliance in order for community benefits agreements to be considered successful.
\end{abstract}

Key words: community benefits agreements; light rail transit; transportation; construction; social costs 


\section{ACKNOWLEDGEMENTS}

I would like to thank my supervisor Dr. Mitchell Kosny, and my second reader Chris Drew for their incredible patience, encouragement, support and insight. I would also like to thank my family and friends for their constant love and support. This research paper is dedicated to my late father, David Culp and my mother Katherine Culp. 


\section{TABLE OF CONTENTS}

Author's Declaration for Electronic Submission of MRP ......................................... ii

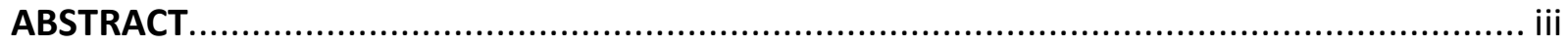

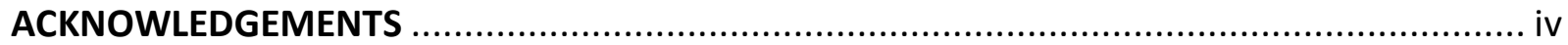

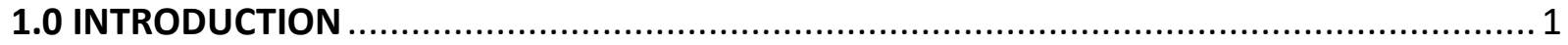

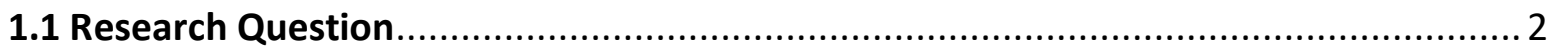

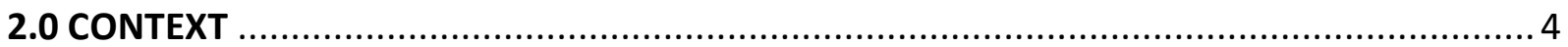

2.1 Community Benefits Agreements (CBAs) .................................................. 4

2.2 Infrastructure for Jobs and Prosperity Act..................................................... 6

2.3 Bill C-344: An Act to amend the Department of Public Works and Government Services Act (community benefit) .................................................................... 7

2.4 City of Toronto's Social Procurement Program ............................................... 8

2.5 Land Value Capture \& Financial Tools .................................................................. 9

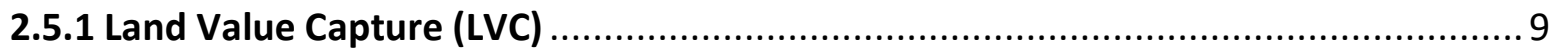

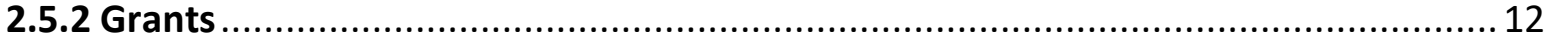

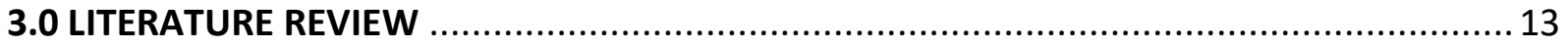

3.1 Social Costs/Mitigation of Construction ...................................................... 13

3.2 Implementation of CBAs to Mitigate Social Costs of Construction .......................... 15

3.3 How to Enable Community Benefits.................................................................. 15

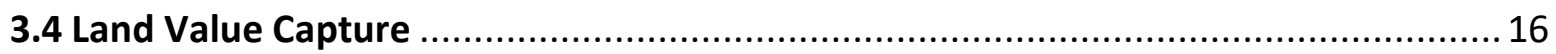

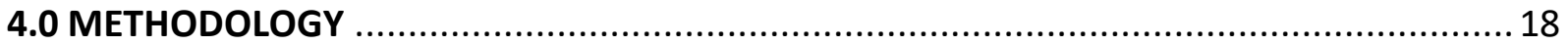

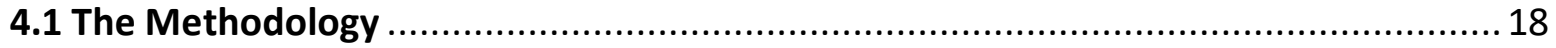

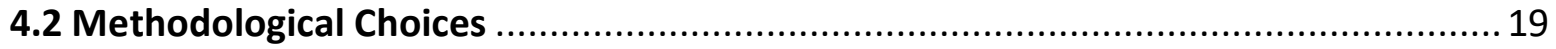

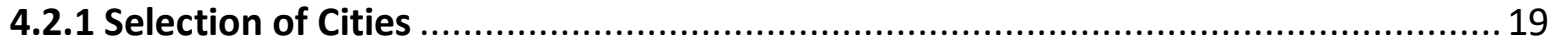

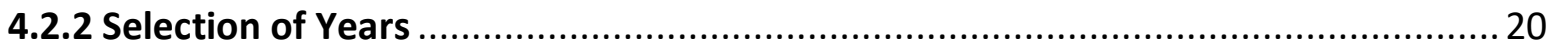

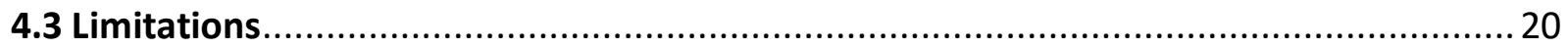

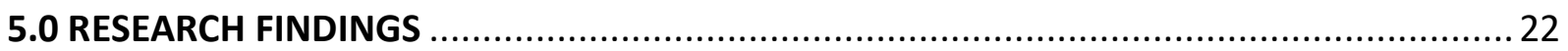

5.1 Evaluation \& Implementation of Community Benefits Agreements ...................... 22

5.1.2 Four Key Criteria for Evaluating Community Benefits .................................... 22

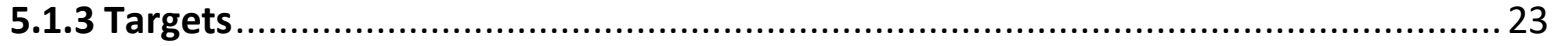

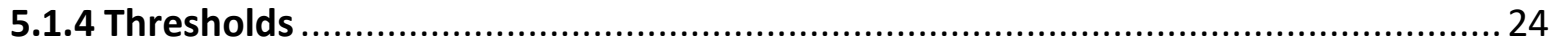

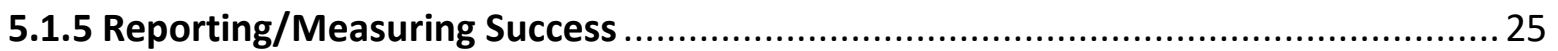

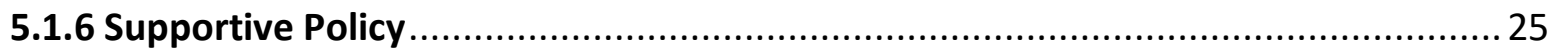




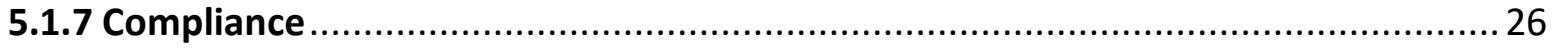

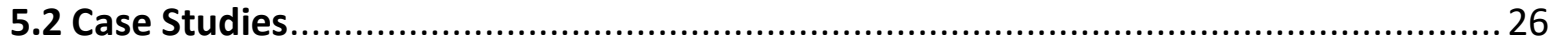

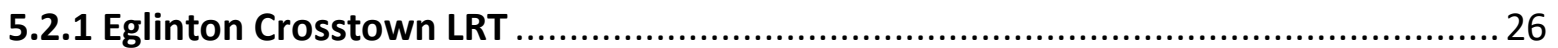

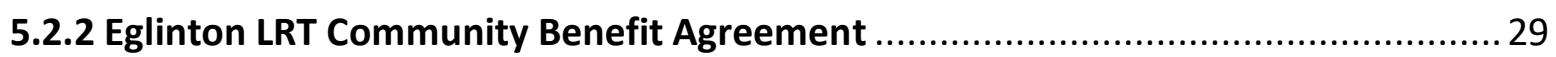

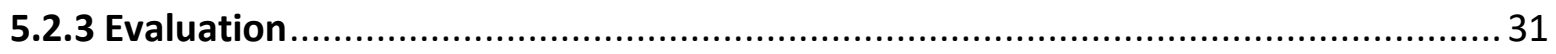

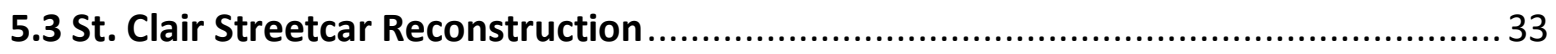

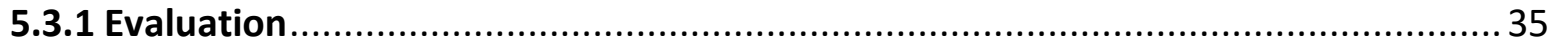

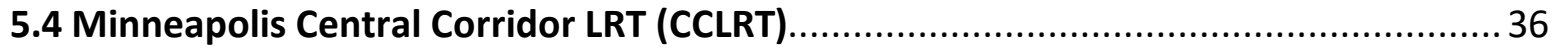

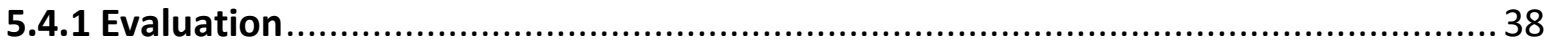

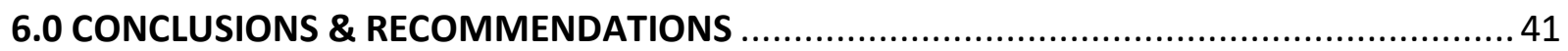

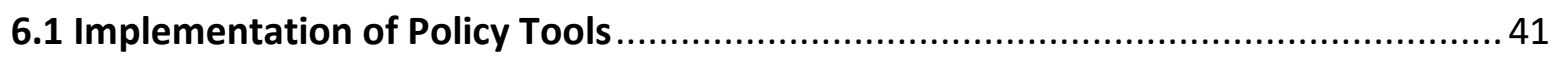

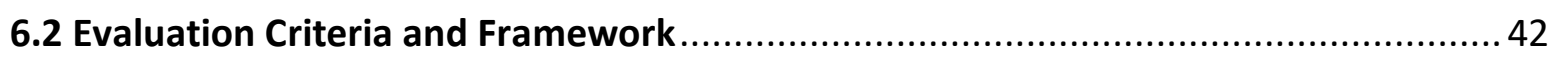

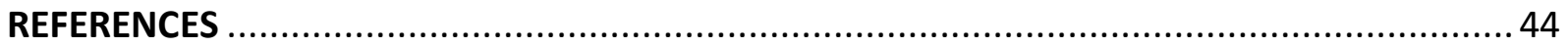




\section{FIGURES}

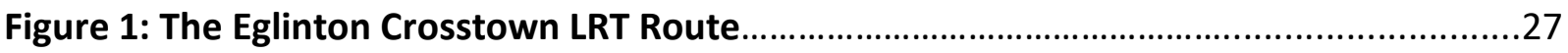

Figure 2: Toronto's NIAs Located along Eglinton Crosstown LRT Route ..................................31

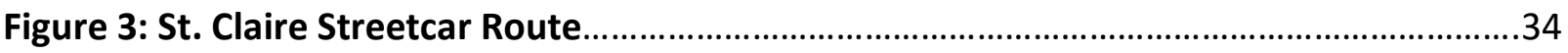

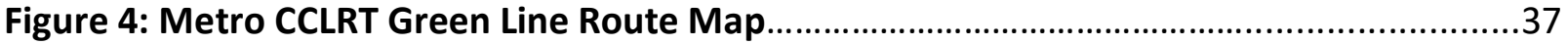




\subsection{INTRODUCTION}

Light Rail Transit (LRT) projects are being implemented throughout the province of Ontario; and are either under construction or set to begin within the next five to ten years. These projects will bring multiple benefits to communities including increased property values, improved accessibility and connectivity and increase financial gains for local business, once completed. Often overlooked, are the social costs of construction of higher order transit infrastructure projects (Gilchrist and Allouche, 2005; Topalovic, et al., 2012). This paper examines how planners can utilize planning policy tools of Community Benefits Agreements (CBAs) and financial policy tools including grants and land value capture to offer solutions to help mitigate the long-term socio-economic costs of transportation infrastructure projects for affected communities.

This issue is assessed by conducting an examination of the literature to explore existing CBAs; grants and land capture tools used by LRT projects in Toronto and Minneapolis. The specific case studies that will be examined include the Eglinton Crosstown in Toronto; St. Clair streetcar reconstruction in Toronto; and Minneapolis' Central Corridor LRT in Minnesota. It examines their mitigation strategies to determine whether similar solutions should be utilized to guide the various planned LRT projects in Ontario. These specific LRT projects were selected because they have been or will be completed within the last ten years, have adequate data, and offer different solutions to mitigate the social impacts and economic impacts faced by local businesses and residents during construction of LRT infrastructure. 
Social costs are defined as "the monetary equivalent of consumed resources, loss of income and loss of enjoyment experienced by parties not engaged in the contractual agreement, solely due to a construction process" (Gilchrist and Allouche, 2005, p 89). Costbenefit analysis is completed for projects by Metrolinx, the provincial transportation agency for the Greater Toronto Hamilton Area (GTHA), to assess the potential impacts and severity transportation projects may have on the community and surrounding landscape. However, there is a lack of understanding of which tools are most effective to account for the social impacts that occur during the construction and post-construction phases of LRT infrastructure development.

Although other North American cities offer incentives and reimbursement policies/programs to those most affected during construction of transportation infrastructure projects, this is not prevalent within the Canadian context. Given this resurgence in LRT prioritization in cities within the GTHA, there is a prime opportunity for further research to be done to better understand the effects of higher order transit, specifically LRTs on livability and vitality of communities and how planning policy and financial tools can be used to mitigate negative impacts.

\subsection{Research Question}

The following research question will be explored: how can planners strengthen and utilize existing planning policy and financial tools to offer solutions to help mitigate the social costs of transportation infrastructure projects for the affected communities? Two sub-questions will be used to help address this larger research question. They are as follows: 
1. How can planners evaluate social costs of construction; and

2. What mitigation strategies have been used to date/could be used by government agencies

and/or businesses and communities themselves to offset the impacts of the construction of LRT?

This is an important question because there is a timely prioritization and resurgence towards LRT construction within the province, despite limited research conducted on the socioeconomic costs of such higher order transit construction within the Canadian context. This research is intended to provide scholars, policymakers and community advocates with a better understanding of the existing planning and financial policy tools used to mitigate socioeconomic costs. 


\subsection{CONTEXT}

Over the next decade billions of dollars will be invested in transit infrastructure which will provide an influx of wealth to communities throughout the region, however, not all communities will benefit equally. In order to help combat these inequities, there has been an increasing interest in "community wealth building" strategies by local advocacy groups and municipalities (Galley, 2015). Community wealth building strategies focus on building community assets, local capacity for businesses, and providing skills and employment for communities impacted by these largescale infrastructure projects (Galley, 2015).

There are a variety of tools used to help build community wealth. Community Benefits Agreements, provincial policies, and financial tools including grants and loans are three different community wealth building tools that emphasize different outcomes and actors involved in mitigating the social costs of transportation infrastructure. Community Benefits Agreements (CBAs) often are advocated for and developed at a grassroots level, whereas policy and financial tools are developed and implemented from the top down. Each of these three tools are discussed in more detail below.

\subsection{Community Benefits Agreements (CBAs)}

“CBAs are negotiated agreements between a private or public development agent and a coalition of community-based groups...that reflect and represent people who are affected by a large development project" (Galley, 2015). CBA coalitions can be comprised of neighbourhood representatives, advocates, labour unions, social service agencies, faith-based groups along with others (Galley, 2015). Most importantly, CBAs provide requirements and standards of 
procurement and contractual processes to ensure that the benefits of public infrastructure investment reach the communities located where the infrastructure is being constructed (Van Ymeren \& Ditta, 2017). In relation to transportation infrastructure projects, the most common benefits targets for these projects are improving skilled workforce development via training and apprenticeship and economic growth opportunities that contribute to reducing poverty by employing people from low-income or disadvantaged populations.

The presumption of these community-based agreements is that investment in public infrastructure projects can be better leveraged to generate local economic value, in addition to other social and environmental benefits that support government mandates (Van Ymeren \& Ditta, 2017). Through the implementation of CBAs, decision makers can maximize the value of government expenditures by considering how infrastructure projects can help achieve public benefits that are lacking in their communities like improved transit access, long-term skilled employment and environmental protection in conjunction with more traditional considerations such as project cost completion time and service quality (Van Ymeren \& Ditta, 2017).

Developers often enter into CBAs to gain the support of the local community to help advance permissions required from a city or planning authority and prevent delays during the project (Van Ymeren \& Ditta, 2017; Graser, 2016 ). In order for community benefits to support all stakeholders, it is important that the development and design of the policies and frameworks balance requirements and are customized to the project and community where they will be implemented in (Van Ymeren \& Ditta, 2017). Thresholds and targets for specific benefits like local employment targets should also be negotiated from the outset in order to achieve 
favourable outcomes for the community. Without clear benchmarks and targets set upfront, it makes evaluating the outcomes challenging and is more likely to result in unsuccessful outcomes. (Van Ymeren \& Ditta, 2017).

In order to ensure CBAs are delivered most effectively, there should be strong legal and political support for these tools by ensuring that objectives that support CBA values and principles are included in legislation, policies and administrative processes (Van Ymeren \& Ditta, 2017). In the context of Ontario, community benefits can be achieved by inserting community benefits clauses into procurement contracts (Van Ymeren \& Ditta, 2017). By requiring clauses for community benefits to be included in the beginning as part of the contractors bid, it provides an increased likelihood of achieving positive outcomes and targets because the success of their bid becomes contingent on how well they are able to demonstrate their ability to deliver on the proposed benefits. Overall, Community Benefits Agreements offer an improved method to ensuring that benefits accrue locally and encompass wider social policy outcomes in government spending and for procurement of larger infrastructure projects.

\subsection{Infrastructure for Jobs and Prosperity Act}

The Infrastructure for Jobs and Prosperity Act (The "Act") is an important policy that attempts to respond to the negative social impacts that infrastructure projects have on the adjacent community and economy. It responds to these impacts by supporting local job creation and training for the affected communities, provides economic growth, and environmental protection (Infrastructure Ontario, 2016; Infrastructure and Jobs for Prosperity Act, 2015). “The Act" was passed in June 2015 with the goal of support long-term infrastructure planning and 
investment in Ontario (Infrastructure Ontario, 2016; Infrastructure and Jobs for Prosperity Act, 2015). The Act includes principles that incorporate community benefits considerations in infrastructure planning and investment.

One critique of the Act is that the legislation's definition of community benefits is quite broad. For example, Section 9 of the Act does not clearly define the contexts or incidents in which the government will require community benefits commitments or when contractors that bid for procurement will be required to provide an apprenticeship plan for the building or maintenance of infrastructure projects. It also does not make such benefits clauses or agreements mandatory for infrastructure projects (Van Ymeren \& Ditta, 2017; Atkinson Foundation, 2016).

Section 9 does state that the successful bidder must provide the number of apprenticeships that the bidder intends to employ for the project and the methods the bidder will use to support the completion but does not state when this must be submitted and what considered appropriate targets. This lack of clarity surrounding community benefits agreements in the Act is problematic as it does not clearly state or enforce measurable targets or how follow up and monitoring to ensure that community benefits are being included (Atkinson Foundation, 2016).

\subsection{Bill C-344: An Act to amend the Department of Public Works and Government Services Act (community benefit)}

At the federal level, a private members bill (C-344) An Act to amend the Department of Public Works and Government Services Act, is currently under consideration and if adopted, would permit the government to require if they so choose, information on community benefits from contractors who bid on federal projects (Bill C-344, 2017, "Community benefit requirement," 
para. 2). Similar to the provincial Infrastructure for Jobs and Prosperity Act, this proposed bill does not require that community benefits be included, but merely gives the option of permitting a requirement. This is a very tokenistic policy proposal since it acknowledges that community benefits should be considered but not required and it does not hold contractors accountable for not including community benefits in their bids for public infrastructure projects.

\subsection{City of Toronto's Social Procurement Program}

The City of Toronto has introduced a new program that encourage community benefits. The City of Toronto's Social Procurement Program's objective is to provide jobs and enhance economic growth in the City. The program is made up of two components: Supply Chain Diversity and Workforce Development (City of Toronto, 2016). The Social Procurement Policy establishes clear guidelines and tools to ensure that businesses owned by members of disadvantaged groups participate in the bidding process for public contracts. It also aims to ensure that businesses contracting with the city hire and train a diverse workforce (City of Toronto, 2016). This demonstrates the importance of policy and programs in advocating for community benefits and committing to more equitable outcomes for disadvantaged populations during construction of large infrastructure projects.

The policy applies to competitive purchases above $\$ 3,000$ in the City of Toronto. Further, it requires that the successful bidder provide records of workforce development progress and outcomes in addition to a plan for workforce development to be shared with the City of Toronto and the public at pre-determined and agreed upon intervals throughout the contract 
(City of Toronto, 2016). This is an important step in policy and for communities that are facing the pressures of infrastructure construction, like those located along the Eglinton Crosstown. Despite these strides to include more equitable practices for procurement and infrastructure projects for disadvantaged populations, it is still unclear how transparent and accessible these bids and skill development processes are for smaller businesses and disadvantaged populations.

\subsection{Land Value Capture \& Financial Tools}

Financial tools are also used to help fund transportation infrastructure projects and have the ability to help offset some of the associated social costs. While there are many types of financial tools to fund transportation infrastructure, in this section two will be discussed. Land value capture (LVC) will be discussed more broadly in relation to transportation-oriented development (TOD) and grants will be discussed more specifically in relation to LRT, as this is a primary financial tool used in many international examples, including the Minneapolis CCLRT case study discussed later in this paper. In this section each tool is discussed to help provide insights into how financial tools can be used to mitigate the social and economic costs for communities and small businesses.

\subsubsection{Land Value Capture (LVC)}

Land Value Capture (LVC) is a way to capture the increase in the value of land and development generated by the improved accessibility of transportation (Metrolinx, 2013; Medda and Modelewska, 2009). It is often used by governments to fund infrastructure improvements by recovering all or some of the increase in property value generated by these improvements to 
fund the facility. It is commonly used to fund transportation infrastructure like LRT since extra profit or value generated in terms of increased accessibility by these improvements is shared by both the public, the agency providing the transit and those who own the land (Metrolinx, 2013; Medda and Modelewska, 2009). The challenge lies in determining LVC methods that fulfill the needs of the public and private sector and finding projects and places where it will be successful (Metrolinx, 2013).

In order to increase the potential for LVC, a direct connection to land use planning, urbanization, building communities, and service locations must be established (Metrolinx, 2013). This is outlined in the Places to Grow Act in Ontario and emphasizes the importance of having planning policy and regulatory support at the municipal level for Transit Oriented Development (TOD) around transit stations and the promotion of intensification around transit stations that supports communities and the services they need (Metrolinx, 2013).

LVC mechanisms can be classified into two main types: tax/fee based and nontax/non-fee based; also known as development based LVC. Various land value capture mechanisms are available to recapture value such as: land value taxes; special assessments; tax incremental financing; development impact fees; joint development; transportation utility fees (Metrolix, 2013; Smith and Gihring, 2006). For the purpose of this paper we will be examining development- based LVC instruments, which capture these increments through land transactions such as selling or leasing land, development rights, and air rights; making land readjustments; and redeveloping urban areas (Metrolinx, 2013). 
One of the main benefits of LVC tools are that the proceeds can be used to finance infrastructure investments as well as other enhancements necessary to offset the impacts related to changes including densification and utilize public policy to promote social equity by including conditions to require affordable housing in exchange for increased height and density of development. (Suzuki, Murakami, \& Hong, 2015). Further, they can provide direct revenue from increases in land value from transit investment but also long-term sustainability of revenue from surrounding amenities like shops, parks, parking and residential buildings which all contribute to increased ridership from Transit-Oriented Development (TOD) (Suzuki, Murakami, \& Hong, 2015).

In the case of LRT construction, development based LVC can provide value added density for developers by allowing increased density in exchange for provision of affordable housing units in the development the developer is proposing in order to reduce gentrification and account for social costs that often are incurred as a result of value added services and infrastructure being implemented in a community (Metrolinx, 2013; Suzuki, Murakami, \& Hong, 2015). In terms of mitigating social costs of LRT construction, development based LVC can offer opportunities for governments and transit agencies to negotiate with private developers in order to offset some of the social costs, like displacement of renters, by creating a contribution agreement that requires affordable rental units to be incorporated into transit oriented development in exchange for the air rights or higher density allowances for the developer (Metrolinx, 2013). 


\subsubsection{Grants}

Grants are another financial tool often used by government organizations to fund transit projects and address the social and economic impacts of construction of such projects (Richardson, 2014; British Columbia Ministry of Municipal Affairs and Housing Services, 2017). Grants simply allow for the transferring of money from one organization to another (British Columbia Ministry of Municipal Affairs and Housing Services, 2017). There are two types of grants: 1) conditional grants and 2) unconditional grants (British Columbia Ministry of Municipal Affairs and Housing Services, 2017).

Conditional grants transfer funds for a particular purpose and may not be used to fund any other project (British Columbia Ministry of Municipal Affairs and Housing Services, 2017). Unconditional grants, can be used by the recipient for any project or purpose (British Columbia Ministry of Municipal Affairs and Housing Services, 2017). Grants for small businesses and communities most affected by TOD are not traditionally used in the Canadian context but are known to be used more so in the American context to help compensate local businesses impacted by construction and ensure that the needs of the local community continue to be met. Conditional grants have been successfully used to provide money for façade upgrades and compensation to small businesses that can demonstrate a clear loss of profit from the construction of LRT projects in order to help small businesses reap the benefits of the project. 


\subsection{LITERATURE REVIEW}

The literature examined to date can be separated into two themes in which it is most commonly discussed. They are: social costs/mitigation of construction of infrastructure and transit and land values. Below is a summary of the findings based on the abovementioned categories.

\subsection{Social Costs/Mitigation of Construction}

There is existing literature that looks at ways to mitigate the negative impacts that construction of light rail has on local business as well as reports that seek to account for social costs, however, there is a lack of consistency of defining social costs and valuing such costs as well (Richardson, 2014; Widener, 2013; Gilchrist and Allouche, 2005). Gilchrist and Allouche (2005) attempt to address the necessity of valuation of social costs and argue that direct valuation techniques should be incorporated into the cost estimate and bid evaluation process from the onset in order to mitigate social costs. Gilchrist and Allouche (2005) recommend direct valuation measures of Loss of Productivity; Human Capital; User Delay Costs be used to help alleviate the challenges communities face during construction of LRT projects. By quantifying the abovementioned measures, it can help track some of the social impacts faced by communities during the construction of transportation project and helps hold contractors accountable to providing these benefits.

Other solutions to help offset the impacts of LRT construction on small business mentioned in the literature include loans and grants, marketing strategies, and facade improvement loans (Richardson, 2014). Various LRT infrastructure development construction projects in the 
American context have offered both grants and low-interest loans in varying amounts ranging from $\$ 200$ to 100,000 (Richardson, 2014). In order to qualify for these loans and grants, businesses were assessed based on revenues, proximity to construction and the length of the project (Richardson, 2014). These grants and low-interest loans have proven to be successful in helping alleviate financial hardship for small independent businesses located along LRT construction routes.

There has also been discourse in the literature challenging the regulatory language used in these newly emerging social policies. Van Ymeren \& Ditta (2017) critique existing legislative and regulatory language as being framed as non-compulsory in community benefits agreements. Van Ymeren \& Ditta (2017) argue that majority of policies that include community benefits request "consideration" of community benefits in contracts, as opposed to requiring contracting authorities to include them in all circumstances. This is problematic since it is the populations in which community benefits agreements advocate for, which are often lowincome, disadvantaged populations that traditionally have faced discrimination and exclusion in participating in such projects and programs, that will continue to be excluded from acquiring these benefits if community benefits agreements are not considered compulsory by contractors. By including regulatory language in policy that enforces and requires inclusion of community benefits, it ensures that these benefits are more likely to be successful and have stronger contributions to the communities that are directly affected by the construction of the project. 


\subsection{Implementation of CBAs to Mitigate Social Costs of Construction}

The literature also notes various ways of implementing CBAs to help mitigate the social costs of large scale infrastructure projects. The literature highlights two main approaches to advocating and securing CBAs. Firstly, there is a bottom-up, grassroots approach whereby local advocates and agencies partner with private partners like developers of large scale infrastructure projects to include agreed upon benefits for the local community in exchange for their support of the project (Graser, 2016; Van Ymeren \& Ditta, 2017). Secondly, a top-down approach that is driven by government and uses policy to enforce the inclusion of community benefits to address the social costs of construction for affected communities (Van Ymeren \& Ditta, 2017; Graser, 2016).

The former approach often supports more transparent and inclusive engagement and include a variety of community benefits, beyond workforce training and utilizing local suppliers for construction of the projects. The latter approach generally has more standardized requirements in terms of thresholds and has more robust and consistent documentation of processes, methodologies and their impacts.

\subsection{How to Enable Community Benefits}

Implementing community benefits requires consistent coordination between government stakeholders and external partners to adapt and develop new objectives into existing legislation and policies (Van Ymeren \& Ditta, 2017). It is important that legislation supports community benefits approaches and clearly states when they are to be included enable legislated approaches. By enabling supportive legislation, it establishes clarity for policy makers on the 
types of outcomes and benefits desired and encouraged by government and offers a clear rational for inclusion into procurement contracts and bids.

\subsection{Land Value Capture}

Many authors found a correlation between LRT and land values, with many suggesting that LRT in many cases increases land values (Topalovic et al., 2005; Hess and Almeida, 2007). Hess and Almeida's (2007) study took this further, indicating that land values have the potential to increase at LRT station nodes anywhere from one year prior to construction and three years post- announcement of plans.

Grube-Cavers \& Patterson (2015) study also found that not only did it increase land values, but LRT also encouraged gentrification in many neighbourhoods noting that exposure to rail transit stations in urban areas increased the likelihood that the census tract would experience gentrification in Toronto and Montreal. This raises concerns and identifies a gap in implementation/development strategy since the very people in which these projects are to help, in terms of increased mobility, connectivity and feasibility, often get displaced and priced out of their neighbourhoods shortly after completion and face numerous disruptions during construction.

Topalovic et al., (2005) note that LRT infrastructure can encourage urban development in cities and has been shown to revive declining areas through changing the pattern of development. As Foth (2010) found in the case of Vancouver's Sky Train, neighbourhoods located near stations increased in density, wealth and overall education levels of population, but cautions that such 
changes are not solely due to LRT infrastructure alone and that incentives, supportive policy, rezoning, and favourable economy all contribute to this trend. 


\subsection{METHODOLOGY}

\subsection{The Methodology}

This research is positioned to build on previous studies conducted on assessing the social costs of LRT construction. This paper uses a case study approach to assess the overall effectiveness of using community benefit agreements, grants, and land value capture tools to mitigate the socio-economic costs of LRT construction. A systematic review of the literature and existing policy has been conducted to help determine the advantages and disadvantages of these tools. Both scholarly, peer reviewed, and non-scholarly sources were examined. The literature review focussed predominantly on the North American context due to its relevancy and similarity to the context of the case studies. Upon the initial scan, these parameters were expanded to include the United Kingdom in relation to CBA evaluation and ability to address the social costs of LRT construction since there is a growing literature and documentation of implementing such measures in these areas. Preference was given to articles that were peer reviewed due to their reliability. Non-scholarly sources were only selected if they examined a specific case study in detail or where there was limited information available in the scholarly literature. A literature review and case study approach was selected as the primary method of research due to its cost-effectiveness, its timeliness and its ethical reliability. 


\subsection{Methodological Choices}

\subsubsection{Selection of Cities}

Three case studies are used to highlight different mitigation strategies for offsetting the social and economic costs faced by communities and small businesses during LRT construction. These cases include: Minneapolis Central Corridor Light Rail Transit Project (CCLRT); Eglinton Crosstown LRT and St. Clair streetcar reconstruction. These were selected due to their similarities in the kind of transportation constructed, their ability to highlight unique strategies for small owner-occupied businesses and residents that are affected through these projects and unique mitigation strategies and have been or will be complete within the last/next ten years. Further, each of these projects are located in proximity to a number of neighbourhood improvement areas which can offer insights into transportation equity and incorporation of social costs for less affluent communities.

Eglinton Crosstown LRT was selected because it is currently under construction in Ontario, it is the first LRT project to include CBAs in construction, and there is sufficient data and literature available. St. Clair streetcar reconstruction was selected because it has been completed within the last ten years in Ontario, there is sufficient data and literature on it, and it emphasizes the outcomes and negative impacts transportation construction can have on communities when social costs and community benefits are not included in procurement. Minneapolis was selected due to its comparable proximity to a number of neighbourhood improvement areas located along the green line, the availability of reliable data, as well as the unique approach of using funding tools instead of CBAs to address the social costs of LRT construction. 


\subsubsection{Selection of Years}

The ten-year span of 2010-2021 was selected because this is when an increase in LRT construction occurred in North America and is expected to continue as shown in the number of projects expected to be completed in Ontario within the next ten years. Each of the case studies was constructed during different periods within this ten-year period and highlights the differences in approaches to addressing social costs in LRT construction over time. By using relevant projects within this timeframe, it is expected that it will offer a more accurate depiction of what tools can be used to mitigate the social costs of construction.

\subsection{Limitations}

One key limitation in the research methodology is the limited availability and standardization of evaluation criteria available for assessing and valuing social costs. This made it challenging to assess the different case studies strength of each cases ability to respond to the social benefits. Another limitation is the case studies themselves. Two are located within Toronto and one is located in the United States which demonstrates the diversity of policy and perspective but did make it challenging to compare. Despite this, the lessons that each provides outweighed the limitations.

Using a systematic literature review as the main method of assessment made it challenging to assess the outcomes and overall effectiveness of each case study. This was mainly due to the lack of standardization and requirement of valuing social costs in transportation projects and limited research that used in-person interviews and/or other qualitative research designs to provide insights into the impacts of transportation infrastructure construction on local 
communities. In person interviews with local business owners and community members may have offered stronger insights into the effectiveness of particular tools in valuing the social costs of LRT and their impacts. 


\subsection{RESEARCH FINDINGS}

\subsection{Evaluation \& Implementation of Community Benefits Agreements}

As LRTs grow in popularity across the region to improve transportation for citizens, it will become increasingly important to develop a means for evaluating the social impacts and ways to equally enhance the neighbourhoods which are affected by the construction of these projects. Presently, CBAs developed for transportation projects lack standardized evaluative frameworks and are assessed on a case by case basis. The following section will provide an overview of different approaches and elements and measures that could be used to inform future work on establishing such an evaluation.

Most jurisdictions do not have evaluative tools for measuring community benefits. Particularly, evaluating the long-term impacts of impacts of community benefits clauses in contracts and social enterprise organizations, measures to mitigate the negative impact that transit-driven development has on marginalized residents living near a project due to gentrification pressures are the most challenging to assess.

\subsubsection{Four Key Criteria for Evaluating Community Benefits}

To understand the impact of community benefits activities, policymakers may consider adopting a high-level evaluation framework that clearly outlines key areas of focus in relation to desired social objectives to be achieved through community benefits approaches. A clear strategy document that clarifies how outputs will be measured, how the information will be supplied by the contractor and how to verify the data can be applied to all future contracts in order to monitor the success of the community benefits (Van Ymermen \& Ditta, 2017). 
Most jurisdictions do not have evaluative tools for measuring community benefits. Particularly, evaluating the long-term impacts of impacts of community benefits clauses in contracts and social enterprise organizations, measures to mitigate the negative impact that transit-driven development has on marginalized residents living near a project due to gentrification pressures, are the most challenging to assess.

Effective community benefits evaluations should include four key criteria:

1. Specific, tangible, meaningful benefits and clear targets to achieving each benefit;

2. Thresholds that clearly state when community benefits should be applied (i.e projects that cost over $\$ 100,000$ dollars etc.);

3. Consistent reports of the outcomes of the community benefits; and

4. Compliance regulations that clearly state what the contractor is required to provide, the consequences if they fail to deliver, and how this will be enforced.

The following section explains these principles and their application, which may help protect against the misuse of the CBA tool.

\subsubsection{Targets}

Specifying clear, tangible, manageable and meaningful benefits is important in evaluating the success of community benefits (Van Ymeren and Ditta, 2017; Graser, 2016; Galley 2015).

Further, developing clear, measurable targets for how these benefits will be achieved is critical to achieving successful outcomes for communities. Targets can be measured in various ways including tracking the number of workforce employed on the project that is from the local 
community and/or disadvantaged populations etc. or the number of work hours given for disadvantaged workers, which can easily be certified through payroll records from the contractor and can determine whether targets are being met on a regular basis (Van Ymeren and Ditta, 2017; Graser, 2016; Galley 2015).

\subsubsection{Thresholds}

Threshold levels at which community benefits should apply to transportation projects should also be included in evaluation criteria (Van Ymeren and Ditta, 2017). Thresholds indicate when benefits should be applied to a particular contract and often are determined by the cost of the project. Typically, thresholds are used on large scale projects and are less common in smaller scale projects (Van Ymeren and Ditta, 2017; Graser, 2016; Galley 2015). Transportation authorities may decide to consider community benefits requirements when projects are located within communities with a particular proportion of low-income residents or if the project is expected to include a particular amount of labour hours (Van Ymeren and Ditta, 2017; Graser, 2016; Galley 2015).

Jurisdictions often have required community benefits to report outcomes or provide clear community benefits in projects that range in value from projects that are valued at more than 4 million in European examples and starting at $\$ 75$ million in certain American examples (Van Ymeren and Ditta, 2017; Graser, 2016; Galley 2015). In the Ontario context, thresholds could align with existing Alternative Financing and Procurement (AFP) thresholds of 100 million dollars, as used by Infrastructure Ontario as a starting point for provincial-wide projects where 
as smaller scale, more localized projects may consider more policy-based implementation measures for lower valued contracts (Van Ymeren and Ditta, 2017; Graser, 2016; Galley 2015).

\subsubsection{Reporting/Measuring Success}

In order to achieve successful outcomes and long-term benefits, all community benefits should be tracked and reported. Reporting is important to demonstrate outcomes and transparency and can help in achieving standardization of evaluations across multiple projects which can help with assessing the long-term impacts of community benefits (Van Ymeren and Ditta, 2017). It should be clearly established at the beginning of a contract how frequent results will be reported, and it is suggested that reports should be completed at least once a year (Van Ymeren and Ditta, 2017). Community benefits reporting should include key performance indicators that are standardized to enable accumulated data collection and performance monitoring across the entirety of the project and potentially similar projects as well (Van Ymeren and Ditta, 2017).

\subsubsection{Supportive Policy}

Embedding community benefits within existing high-level municipal policy or developing new policies where community benefits are supported by policy will help ensure more successful outcomes for communities (Hanff, 2016). By supporting the provision of community benefits in planning policy, it helps bolster their importance and helps provide more robust, requirements in terms of when they should be applied, how they are documented and their overall impacts. 
This can be evaluated by requiring the contractor to demonstrate how the aligns with existing policy and government goals and the more a contractor clearly demonstrates this, the more likely they will be in securing the contract for the project. Further, by requiring community benefits to be considered as part of the planning process, developers and communities will be more likely to expend resources negotiating and implementing them, which is more favourable for all stakeholders (Hanff, 2016).

\subsubsection{Compliance}

It is important to hold contractors accountable for their commitments to community benefits. Compliance of the CBA can be enforced through non-compliance mechanisms or penalties if contractors are failing to meet their benefits targets, and bonuses can be provided if contractors are achieving and/or exceeding targets. Some penalties bar contractors from receiving future contracts in cases of serious non-compliance and highlight the importance of providing the community benefits agreed upon. Compliance can be evaluated by tracking the community benefits targets set out in the contract and clearly stating the consequences for failing to achieve community benefit commitments. Without clearly establishing compliance of providing community benefits, community members will continue to be forced to absorb the negative social outcomes of construction costs with no compensation.

\subsection{Case Studies}

\subsubsection{Eglinton Crosstown LRT}

The Eglinton Crosstown LRT is an LRT line presently under construction in Toronto that is $19 \mathrm{~km}$ length and runs along Eglinton Avenue between Mount Dennis and Kennedy Station (Metrolinx, 
2016). It will include 25 stations and stops while also connecting to local bus and subway stations as well as GO Transit as shown in Figure 1. (Infrastructure Ontario, 2016). The Eglinton Crosstown combines above ground and underground alignment; with $10 \mathrm{~km}$ of the project set to be underground from Keele Street to Laird Drive (Metrolinx, 2016). This project began construction in 2011 and is expected to be completed in 2021 (Metrolinx, 2016). The project is being delivered by Metrolinx but procurement is being managed by Infrastructure Ontario (IO) through the Alternative Financing and Procurement (AFP process) (Metrolinx, 2016; Van Ymeren \& Ditta, 2017).

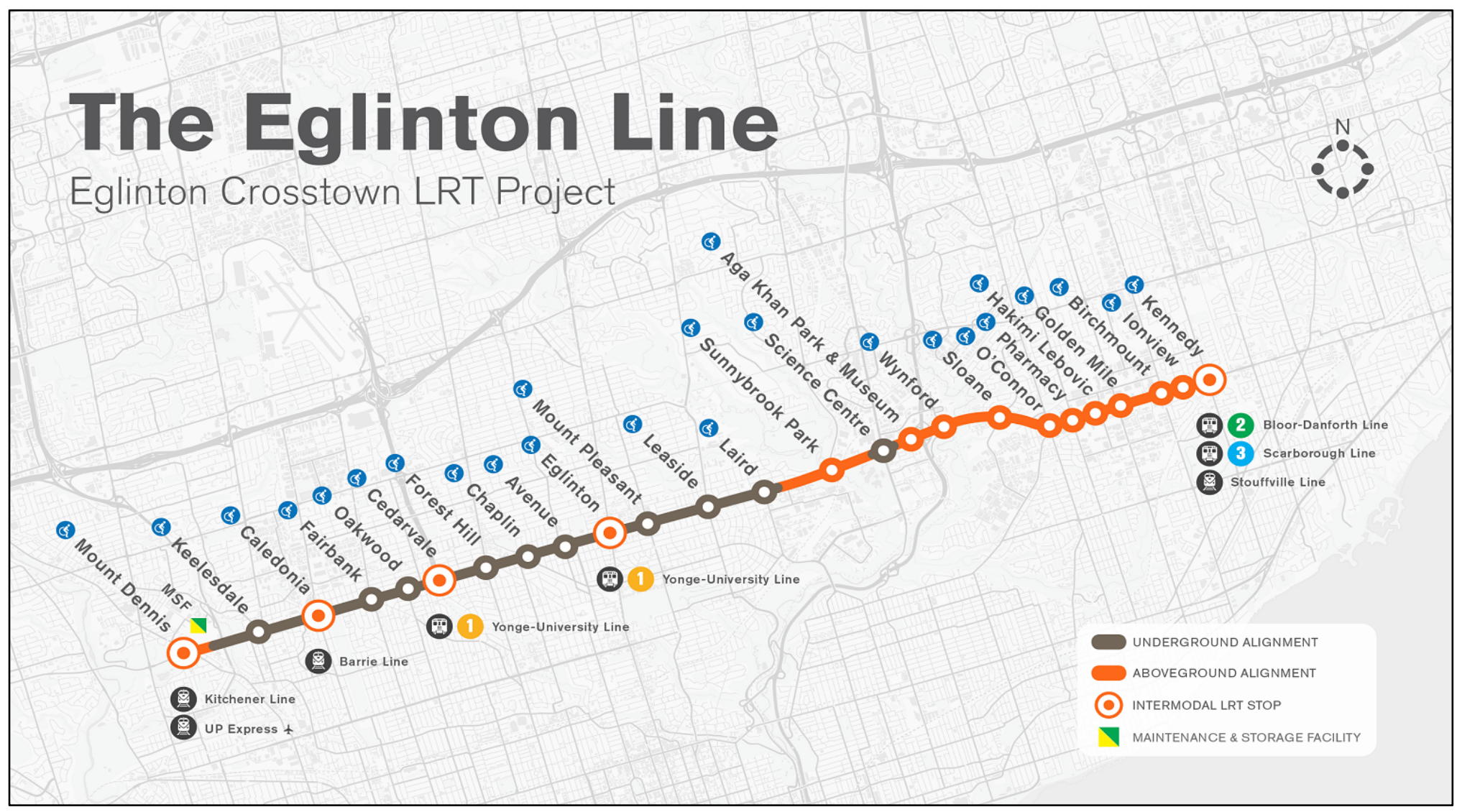

Figure 1: The Eglinton Crosstown LRT Route (Metrolinx, 2016) 
The Eglinton Crosstown LRT project has committed to providing community benefits agreements for this project. Primary signatories include the Toronto Community Benefits Network (TCBN) and Metrolinx (Galley, 2015; Metrolinx, 2016). Metrolinx is the provincial agency responsible for regional transportation in the GTHA. The support for a CBA for the Eglinton Crosstown came about in response to the line's route which crosses through neighbourhoods identified as Neighbourhood Improvement Areas (NIAs) as shown in Figure 2 (Galley, 2015; Metrolinx, 2016). The coalition for this project advocated that the project should provide economic opportunities for residents and businesses in these affected areas (Galley, 2015). The Eglinton Crosstown LRT is the first CBA for Metrolinx and will set a precedent for how future infrastructure projects can provide benefits to lower income neighbourhoods and apply across future transit projects in the City and throughout the region (Galley, 2015). The CBA framework outlines a commitment to local hiring and social purchasing in the construction of new transit in Toronto.

In order to incorporate community benefits into the framework of the project, A Community Benefits Working Group has been created to implement community benefits into the project successfully to ensure that affected communities directly benefit from the project (Crosslinx Transit Solutions, 2016). The Community Benefits Working Group membership is open to any community organization, labour organization and workforce development agency in the City of Toronto and to Metrolinx and Crosslinks Transit Solutions (CTS). Presently it includes representatives of Metrolinx, Ministry of Training, Colleges and Universities (MTCU), Toronto Community Benefits Network (TCBN), and CTS (Crosslinx Transit Solutions, 2016). The Community Benefits Working Group meets regularly to provide performance accountability, 
review activities, plans, and initiatives as part of the Community Benefits Framework signed between Metrolinx and the TCBN (Crosslinx Transit Solutions, 2016).

\subsubsection{Eglinton LRT Community Benefit Agreement}

The Community Benefits Program includes a variety of opportunities such as the "Transit in your Community" and "CareerStart" programs which proactively plan to include all members of communities (Crosslinx Transit Solutions, 2016). The Eglinton Crosstown LRT CBA includes a number of community benefits including the development of a construction pathway for apprenticeships, working with the local employment and skill-based agencies, school programs, and commitment to engaging in social enterprise and hosting purchasing information sessions.

In accordance with the CBA framework, CTS will be required to provide a quarterly report on its Community Benefits initiatives. The report will include information regarding the number of job/application referrals received from community partner agencies and positions filled by such candidates; Summary of partnerships and events held within the three NIA areas; Summary of CTS procurements with social enterprises and local businesses and debriefs of events held with local businesses, workforce agencies and social enterprises (Crosslinx Transit Solutions, 2016).

The TCBN has developed five working groups that have been seeking to gain access to training, jobs, commercial opportunities, neighbourhood improvements and to ensure that commitments made by all parties are clear (Crosslinx Transit Solutions, 2016). This is a critical step as it increases accountability of the CBA agreement and ensures that CTS is upholding their commitment to the community. The following working groups are all contributing to the successful implementation of the Community Benefits Program: Construction Trades and 
Apprenticeship Jobs working group; Professional, Administrative and Technical Jobs working group; Social Enterprise working group; Neighbourhood and Environment working group and; Clear Commitments and Accountability working group (Crosslinx Transit Solutions, 2016).

The Community Benefits Agreement along with CTS recognizes the employment barriers facing NIAs, a number of which are in the direct vicinity of the Eglinton corridor (see Figure 2). These include Weston, Mount Dennis, Beechborough-Greenbrook, Rockcliffe-Smythe, KeelesdaleEglinton West, Weston-Pellam Park NIAs in the West; Thorncliffe Park, Flemingdon Park, Victoria Village, Ionview, Kennedy Park, and Eglinton East NIAs (Crosslinx Transit Solutions, 2016). These communities, along with other NIAs in the City of Toronto, have been listed as priority areas for engagement in the community benefits program. This is a significant commitment by CTS and provided the predetermined programs and community benefit options are appropriately delivered, this could become an example and guide for future infrastructure CBA agreements. 


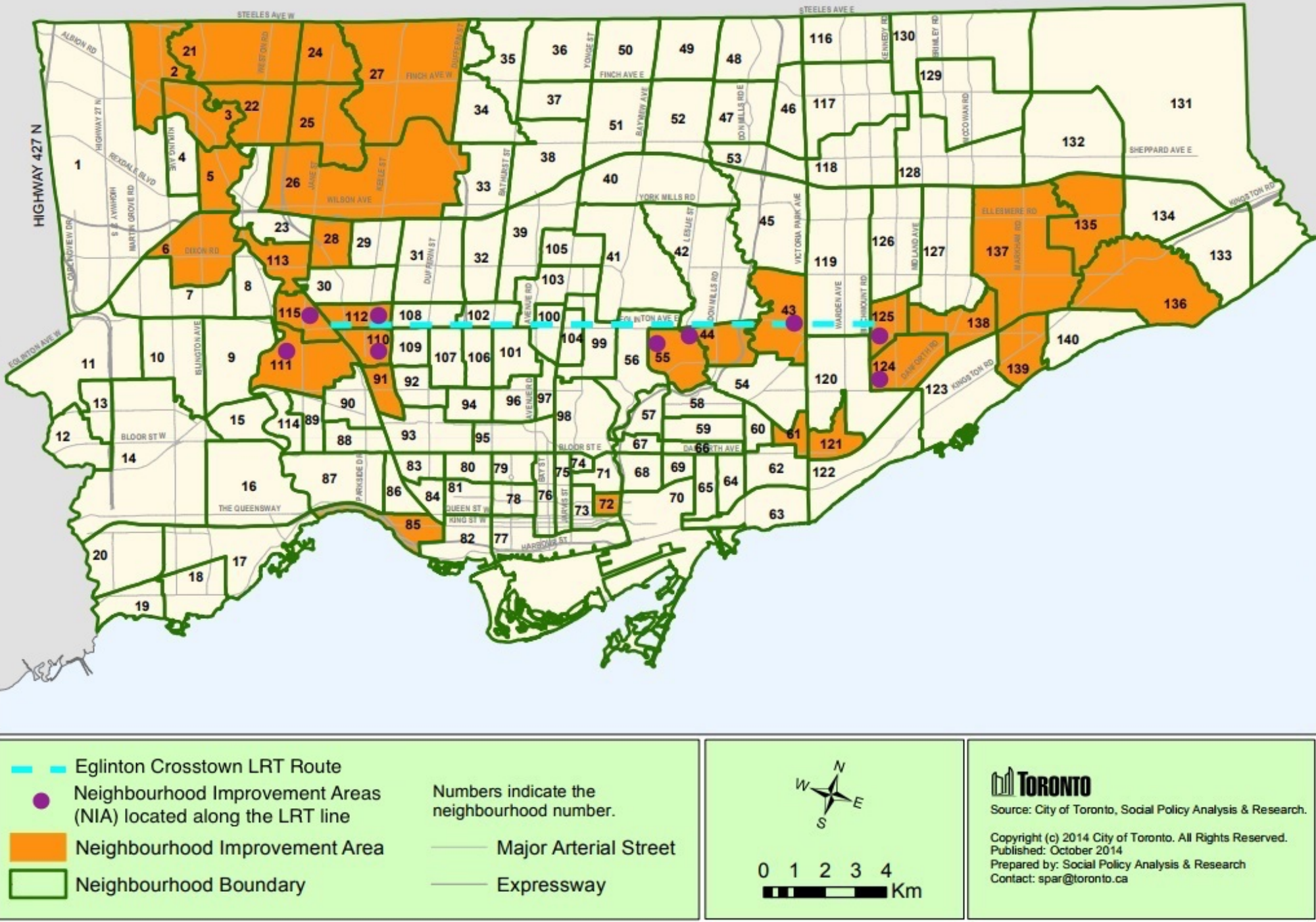

Figure 2: Adapted Map of Toronto's NIAs Located along Eglinton Crosstown LRT Route (City of Toronto, Social Policy Analysis \& Research, 2014)

\subsubsection{Evaluation}

The inclusion of CBA for the Eglinton Crosstown LRT is a strong first step in achieving more equitable outcomes for communities affected by the construction of transportation projects.

The agreement does have targets for employment and specific benefits established but this 
took serious negotiating from the community and was not initially offered (Galley, 2015; Van Ymeren and Ditta, 2017). Through the signing of the Declaration re. Apprentices on the Eglinton Crosstown LRT Project, advocates ensured that apprentices or journeypersons from historically disadvantaged communities perform 10 percent of all trade or working hours needed to construct the LRT (Metrolinx, 2016a). The CBA also did explain how it would seek to engage and involved affected communities mainly in employment and apprenticeship opportunities. This is a good first step to holding Metrolinx accountable to its commitments however, the declaration is not legally binding and relies on good-faith efforts of the partners to ensure these outcomes are achieved. The CBA also does indicate that consistent quarterly reporting on progress. Also, in order to increase accountability and successful outcomes, the CBA ensured Metrolinx hired a dedicated liaison to work with all stakeholders to support the implementation of the community benefits program.

There are no thresholds established in this case, but it is expected that this CBA will act as a precedent for future CBAs for other transportation infrastructure projects such as the Finch LRT. Two reports have been released on the progress of achieving and implementing community benefits for the Eglinton Crosstown LRT project. The reports clearly state their objectives, partners and all forms of engagement activities and number of people who engaged in these opportunities. These activities include employment and hiring info sessions, public engagement and information sessions, volunteering sessions by Metrolinx staff in local communities such as preparing food for families at foodbanks in the Mount Dennis community. The reports also clearly identify the number of people from the Eglinton area communities which are employed to date on the project and also specify the types of positions such as 
professional; technical; administrative. This example shows a balance of commitment and accountability by all stakeholders and is a strong example of how CBAs can mitigate the social costs of LRT construction.

\subsection{St. Clair Streetcar Reconstruction}

The St. Clair streetcar route reconstruction was approved in 2004 to improve service reliability and was fully completed in 2010. This project spans $6.8 \mathrm{~km}$ and provides an exclusive right-ofway streetcar route on St. Clair Avenue between Yonge Street and Gunns loop, as shown in Figure 3 (Kelman \& Soberman, 2010). This case is used to highlight the important challenges and pitfalls of transportation infrastructure projects implementation and the negative impacts that occur by not having community benefits addressed in procurement. Twenty separate construction contracts were awarded for this project which contributed to poor project management and ultimately delays of completion. This had negative consequences for the surrounding communities and local businesses (Kelman \& Soberman, 2010). Further, the timeline for completion was extended to beyond five years which also contributed to huge financial losses for local business owners along St.Clair (Kelman \& Soberman, 2010).

Targets for community benefits were not established from the onset and it was not until formal objections were made by various stakeholders who argued there was a lack of adequate public consultation, and that any attention was paid to involving the community in this project. This resulted in the Ministry of the Environment ordering further consultation with the public as a pre-condition to project approval (Kelman \& Soberman, 2010). 


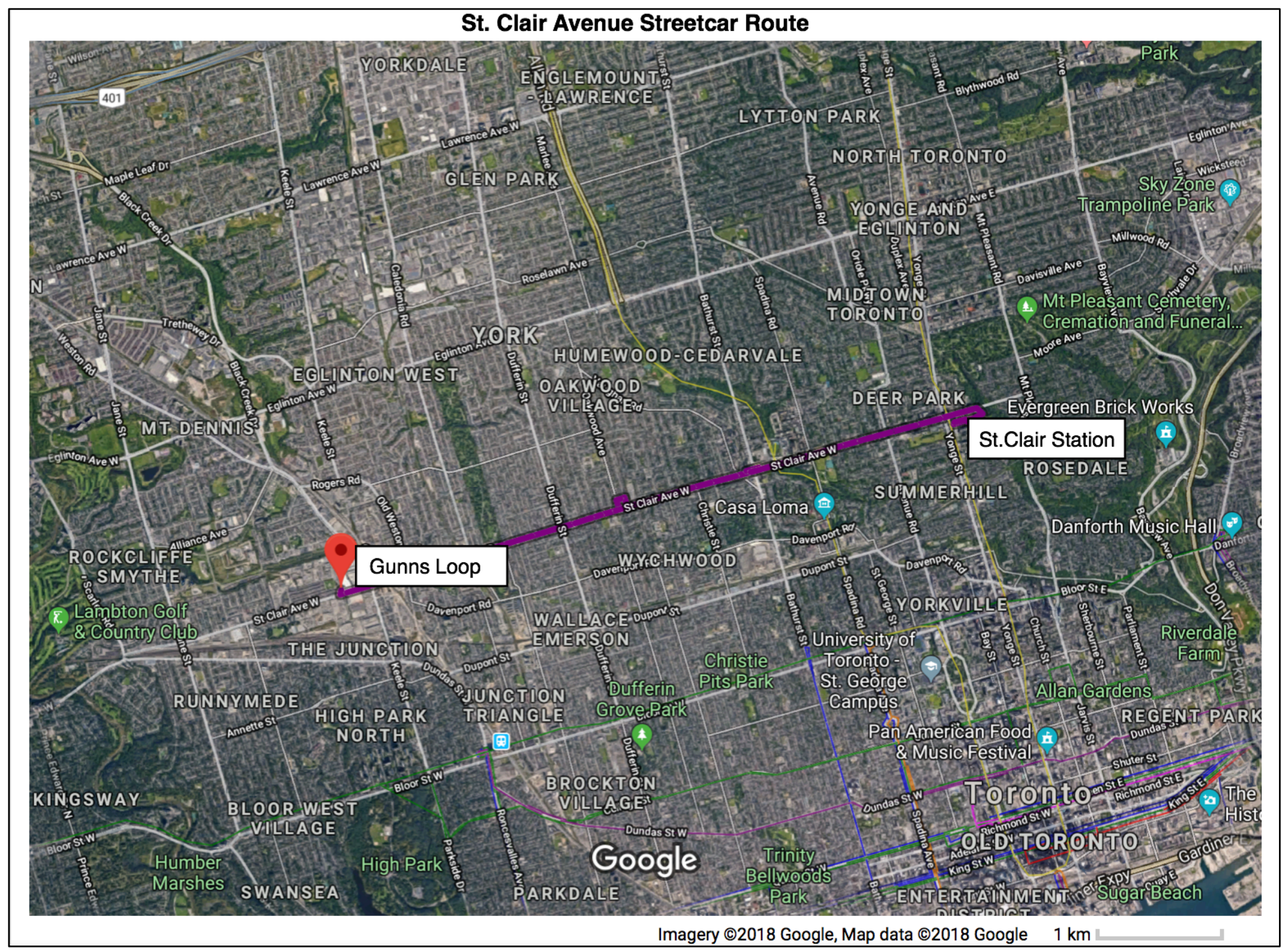

Figure 3: Adapted Map of the St. Clair Streetcar Route (Google Maps, 2018).

A Construction Liaison Committee (CLC) was created for this project and was considered

effective since it helped improve communication and mitigation of small hindrances such as

accommodating local deliveries, parking, communicating with local businesses etc. (Kelman \&

Soberman, 2010). CLC participants included local business owners, residents, school 
representatives, City Councillors and City and TTC consultation and construction staff (Kelman \& Soberman, 2010).

The CLC was responsible for resolving day to day construction issues and ensuring local businesses were aware of planned traffic re-routing in order to provide advance notice to their customers (Kelman \& Soberman, 2010). While the CLC successfully communicated with the community, their capacity to respond to the needs of the community and reduce disruption through construction did fall short. Hiring a community partner liaison to engage with all stakeholders could have helped improve communication and help to ensure community benefits for this project.

\subsubsection{Evaluation}

The lack of community benefits and consultation throughout this project reaffirms the importance of including CBAs in large scale infrastructure projects. By establishing supports for local business and community members such as employing local residents for the project and providing funding and marketing support to assist local businesses, it likely would have reduced many of these negative social outcomes as a result of the reconstruction.

The St. Clair streetcar reconstruction project did not provide any public reports on its progress during the construction period. The CLC would often relay information to the public but minimal documentation of status and progress was shared. After the project was completed, a "lessons learned" report was conducted to discuss the shortcoming of the project. This lack of 
transparency and measurability of the projects progression, was extremely problematic and more should have been done to document and publicise this information.

Compliance was not clearly defined or enforced in this project and it was not until the Ministry of the Environment intervened that the contractors responded. The construction delays due to complaints put forth to the Minister of Environment and the Judicial Review in 2005-2006, had severe hardship for affected residents and businesses. Clear consequences should have been in place from the onset of the project to hold the contractors accountable for failing to effectively complete the project on time and budget and the hardships it caused for local residents. Had this been included, this likely would been considered a more successful project with higher community benefits for St. Clair communities. The St. Clair streetcar reconstruction clearly demonstrates the challenges communities face during construction when community benefit agreements are not formally established for specific transportation construction projects.

\subsection{Minneapolis Central Corridor LRT (CCLRT)}

The CCLRT is an LRT project that underwent construction in 2009 and was complete in 2014 (Richardson, 2014). It spans 11.2 miles connecting Minneapolis and St. Paul and cost approximately $\$ 957$ million dollars, as shown in Figure 4 (Richardson, 2014). Six miles of the project cuts through a major street with approximately 1400 businesses located along it and cuts through multiple ethnic communities, where many residents are on low incomes, do not have cars, and live below the poverty line (Richardson, 2014). 


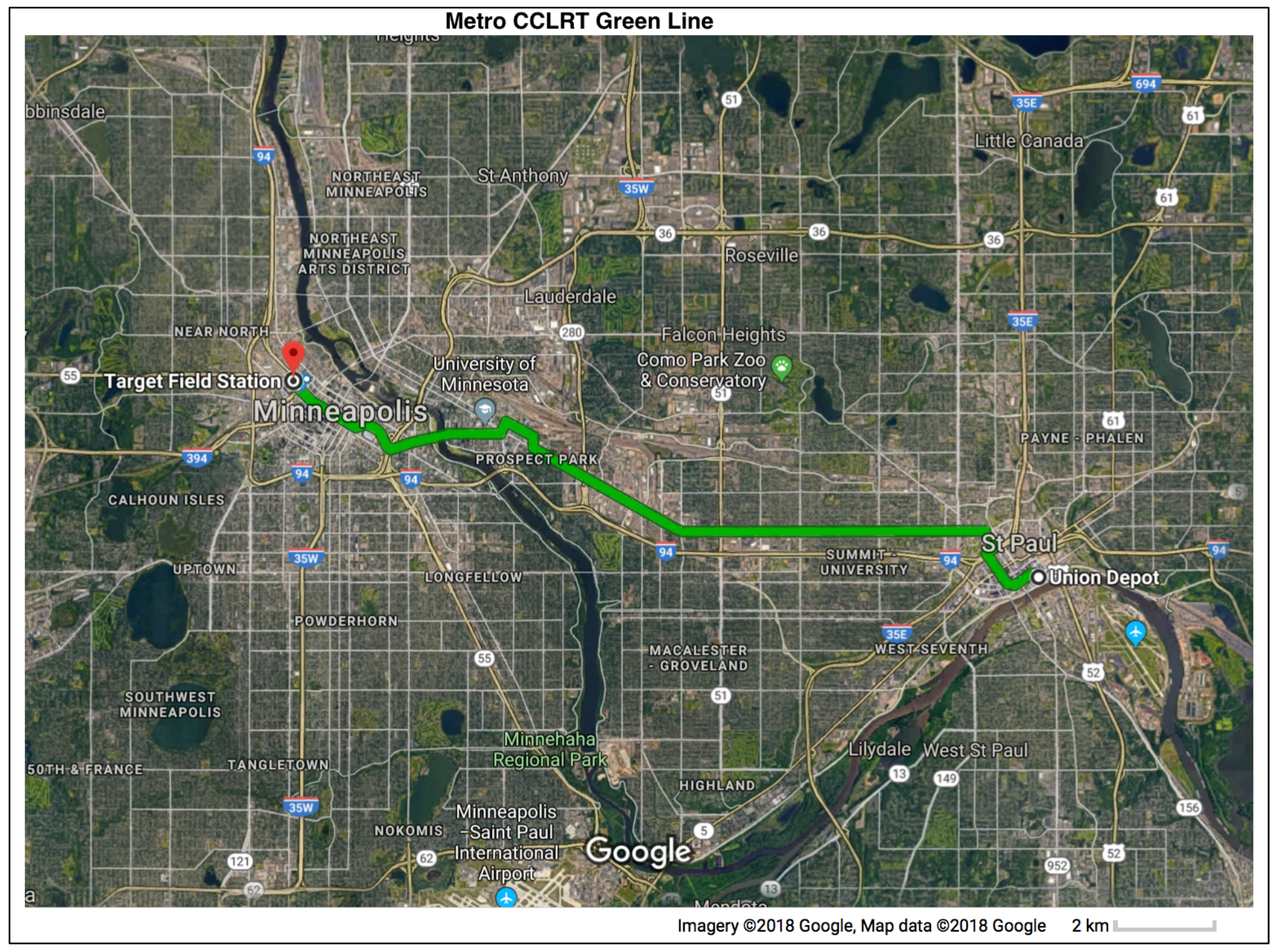

Figure 4: Metro CCLRT Green Line Route Map (Google Maps, 2018a)

Minneapolis' CCLRT utilized financial tools to help alleviate construction related losses for small businesses (Richardson, 2014). Grants were available to help replenish lost revenues, to pay for storefront enhancements and expansion of businesses, and assist in relocation of businesses (Richardson, 2014). These grants ranged in value from micro level grants of $\$ 200$ to larger loans of 150,000 dollars (Richardson, 2014). In order to qualify for these grants, businesses and their 
owners had to meet specific criteria to be considered eligible to receive funds (Richardson, 2014). Eligibility criteria was established for grant applicants (Richardson, 2014). The businesses applying for these grants had to be for-profit and their annual gross sales could not exceed two million dollars; they had to be located within one block of the CCLRT construction or on the CCLRT directly; have remained at their current location for at least one year; and experienced a decline in profit due to construction (Richardson, 2014).

The grants were provided by the Metropolitan Council; the City of St. Paul and the Central Corridor Funders Collaborative for a grand total of 4 million dollars collectively (Richardson, 2014). The maximum sum for the grant was 20,000 dollars per business and was contingent on the demand and ability to prove loss of revenue (Richardson, 2014). While targets were clearly defined for who qualified and the amounts available, only twenty-five percent of businesses could receive this financial grant. This resulted in many under qualified businesses having to seek out other sources of financial assistance such as high interest loans (Richardson, 2014).

\subsubsection{Evaluation}

Clear targets were established from the onset of this project in terms of how much funding was available, who qualified and what funds could be used towards which demonstrates the effectiveness of grants generating community benefits and offsetting some of the costs that small businesses face during construction. However, a critique of this approach is that the 20,000 dollars offered to businesses is not enough for businesses to continue to operate and that more realistic targets and thresholds should have been established (Richardson, 2017). 
The CCLRT also offered grants for business improvements and expansion to highlight the importance of local and minority owned business along the corridor (Richardson, 2014). While this intervention did provide community benefits, it was not reported or tracked to assess how many businesses used the grants for marketing and storefront enhancements. There was also no clear reporting during the duration of the project to highlight progress to date in terms of how many businesses had applied and successfully received funding. By reporting this information more regularly throughout the project, challenges regarding grant amounts, who could use them and what they could be applied to, could have been avoided.

Monetary incentives and bonuses were also provided to contractors, subcontractors and employees for finishing the construction on time or before expected completion, in order to reduce the negative impacts of construction on local communities and businesses (Richardson, 2014). Minneapolis' CCLRT project established committees of business owners, citizens associated with the light rail projects, or in some cases, both to help decide the bonus given to the contractors (Richardson, 2014).

This is a good example of how compliance was addressed in this project and highlights how the actions of contractors and their employees can affect businesses during the construction phase by limiting or increasing the magnitude of construction. Restricting the area under construction, controlling the weeks and hours of construction, upholding access requirements, as well as clean up requirements all could also have been used to help offset the construction costs of LRT on small businesses (Richardson, 2014). 
This example shows how financial tools can be used to gain community benefits and offset the social costs of LRT construction. Future LRT projects for Ontario should consider using grants as well as require CBAs to be embedded in procurement and policy in order to ensure more equitable outcomes for all communities. 


\subsection{CONCLUSIONS \& RECOMMENDATIONS}

Planners need to be aware of the advantages and disadvantages of different planning policy and financial policy tools pertaining to community benefits in order adequately and equitably mitigate social and economic costs for those most impacted by such largescale transit-oriented development projects. This paper showcases how grants, community benefits agreements and policy can offset social costs by offering financial and social support for stakeholders.

\subsection{Implementation of Policy Tools}

This paper also introduced a variety planning policy and financial tools that can be utilized to help bring community benefits to the areas located where these projects will be constructed. CBAs offer a desirable way to increase the positive social and economic impact of infrastructure projects through engagement with affected communities, local procurement and hiring practices, and improved services and facilities. CBAs should be utilized to help ensure that contractors provide community benefits and account for the social impacts of LRT construction. Future research should explore ways to secure grant funding or determine if it can be included in the total cost of the project. Grants should be utilized in conjunction with community benefits agreements to help both small businesses and their community members succeed during the construction of large scale infrastructure projects.

Grants are most successful in mitigating effects when eligibility criteria is easy to comprehend and has few restrictions, so more stakeholders can access them. Ontario LRT projects should look at the successes that Minneapolis and Eglinton LRT projects received through utilizing CBAs, collaborative grants and land value capture tools to offset the negative impacts of 
construction costs of small business and increase the equity and accessibility for all stakeholders in transit-oriented development projects.

\subsection{Evaluation Criteria and Framework}

While this paper discussed some elements that should be evaluated in order for community benefits to be successful, future research should be completed to create a high level best practices guide and evaluative framework that can be used by provincial and municipal governments to evaluate how well the community benefits are being implemented in construction projects to mitigate social costs. This more extensive evaluation framework should include a guide on standardizing data reporting requirements and targets so that communitylevel data and outcomes can be aligned, evaluated and aggregated with other data and initiatives. Evaluation and reporting of the community benefits can also provide opportunities to engage the community in the evaluation process to ensure community benefits are being achieved and are well received.

It is also recommended that in order to achieve the most successful outcomes for affected communities, community benefits should be embedded into existing policy to align with existing objectives. There are existing policies like the City of Toronto Social Procurement Program and the Infrastructure for Jobs and Prosperity Act that can be expanded to include additional community benefits and provide merit to including community benefits in the procurement process.

Clear and specific targets for reaching and reporting benefits should also be established from the onset of establishing a community benefits agreement. Thresholds should also be 
established in order to determine when community benefit agreements should be implemented. It is also recommended that the reporting of outcomes is included in the agreements and measured in the evaluation.

The case studies highlighted the advantages of community benefits agreements, the consequences for communities when social costs are not taken into consideration, and how financial tools can be used to mitigate the social costs of LRT construction projects. It is imperative that with influx of LRT projects planned for cities across Ontario over the next ten years, that cities improve the planning policy and financial tools available so that they can better mitigate the social costs that can result from the construction of such largescale transportation infrastructure projects. 


\section{REFERENCES}

Atkinson Foundation. (2016). Making Community Benefits a Reality in Ontario. Retrieved from http://atkinsonfoundation.ca/wp-content/uploads/2016/10/atkinson cbsummary.pdf

Bill C-344: An Act to amend the Department of Public Works and Government Services Act (community benefit). April 6, 2017, 42 ${ }^{\text {nd }}$ Parliament, $1^{\text {st }}$ Reading. Retrieved from Parliament of Canada website http://www.parl.ca/DocumentViewer/en/42-1/bill/C-344/first-reading

British Columbia Ministry of Municipal Affairs and Housing Services.(2017).Local Government Grants. Retrieved November 18, 2017, from http://www.cscd.gov.bc.ca/lgd/finance/grants.htm

City of Toronto. (2016). Social Procurement Program. Retrieved from https://www.toronto.ca/legdocs/mmis/2016/ex/bgrd/backgroundfile-91818.pdf

City of Toronto, Social Policy Analysis \& Research. (2014). Neighbourhood Improvement Areas. Retrieved from https://www.toronto.ca/wp-content/uploads/2017/10/8fb8-map-of-torontonias-neighbourhood-improvement-areas.jpg

Crosslinx Transit Solutions (2016). Community Benefits and Liaison Plan for Eglinton Crosstown LRT Project. Retrieved from http://thecrosstown.ca/sites/default/files/cts__community_benefits_and_liaison_plan_rev_01_-_february_26_2016_.pdf

Foth, N. M. (2010). Long-term change around SkyTrain stations in vancouver, canada: A demographic shift-share analysis. The Geographical Bulletin, 51(1), 37.

Galley,G. (2015). The Prosperous Province: Strategies for Building Community Wealth. The Mowat Centrre. Retrieved from: http://communitybenefitsagreements.ca

Gilchrist, A., \& Allouche, E. N. (2005). Quantification of social costs associated with construction projects: State-of-the-art review. Tunneling and Underground Space Technology, 20(1), 89-104. doi:10.1016/j.tust.2004.04.003

Google Maps. (2018). St. Clair Streetcar Route. Retrieved April $1^{\text {st }}, 2018$, from https://goo.gl/6xjwHK

Google Maps. (2018a). Metro CCLRT Green Line Route. Retrieved April $4^{\text {th }}, 2018$, from https://goo.gl/su1Gj2

Graser, D. (2016). Community Benefits in Practice and in Policy: Lessons from the United States and the United Kingdom. The Atkinson Foundation. Retrieved from:

http://atkinsonfoundation.ca/wp-content/uploads/2016/09/atkinson_cbreport_fa.pdf 
Grube-Cavers,A., \& Patterson, Z. (2015). Urban rapid rail transit and gentrification in Canadian urban centres: A survival analysis approach. Urban Studies Journal. 52(12). 178-194. DOI: 10.1177/0042098014524287 usj.sagepub.com

Hanff, B. (2016). Bringing Community Benefits to Toronto Neighbourhoods. Unpublished master's thesis, The University of Toronto, Toronto, Ontario. Retrieved from: http://dinagraser.ca/wp-content/uploads/2017/05/Hanff-Ben-CBAs-Final.pdf

Hess, D. B., \& Almeida, T. M. (2007). Impact of proximity to light rail rapid transit on stationarea property values in buffalo, New York. Urban Studies, 44(5/6), 1041-1068.

Infrastructure and Jobs for Prosperity Act, SO 2015, c 15, s 3.

Infrastructure Ontario. (2016). Value for money assessment: Eglinton Crosstown Light Rail Transit. Retrieved from http://www.infrastructureontario.ca/Templates/Project.aspx?id=2147491907\&mode=1\&langty pe $=1033$.

Kelman, L., \& Soberman, R.M. (2010). "Getting it Right" Lessons from the St. Clair Streetcar for the Implementation of Transit City. Retrieved from:

https://www.ttc.ca/About the TTC/Commission reports and information/Commission meeti ngs/2010/Jan_20_2010/Reports/Transit_City_Impleme.pdf

Medda, F. and Modelewska, M. (2009). Land value capture as a funding source for urban investment: The Warsaw metro system. [online] London: University College London. Available at: https://www.ucl.ac.uk/qaser/pdf/publications/ernst_young [Accessed 20 Nov. 2017].

Metrolinx. (2013). Land Value Capture Discussion Paper August 2013. Toronto: Metrolinx. Retrieved from http://www.metrolinx.com/en/regionalplanning/funding/Land_Value_Capture_Discussion_Pap er

Metrolinx. (2016). Eglinton Crosstown. Retrieved from http://www.thecrosstown.ca/.

Metrolinx. (2016a). Declaration Re: Apprentices on the Eglinton Crosstown LRT Project. Retrieved from: http://www.thecrosstown.ca/sites/default/files/crosstown_apprenticeship_declaration_signed .pdf

Richardson, A. (2014). A comparison study of measures to mitigate loss of business revenue during major construction projects. Journal of Affordable Housing \& Community Development Law, 22 (3-4), 267-298. 
Suzuki, H., Murakami, J., \& Hong, Y. (2015). Financing transit-oriented development with land values: Adapting land value capture in developing countries. Washington: World Bank Publications. doi:10.1596/978-1-4648-0149-5

Topalovic, P., Carter, J., Topalovic, M., \& Krantzberg, G. (2012). Light rail transit in hamilton: Health, environmental and economic impact analysis. Social Indicators Research, 108(2), 329350. doi:10.1007/s11205-012-0069-x

Widener, M. N. (2013). Curbside service: Community land use catalysts to neighborhood flowering during transit installations. The Urban Lawyer, 45(2), 407-447. Retrieved from http://ezproxy.lib.ryerson.ca/login?url=http://search.proquest.com/docview/1462498213?acco untid $=1361$

Van Ymeren, J., \& Ditta, S. (2017). Delivering Benefit: Achieving Community Benefits in Ontario (Report No. 153). Retrieved from: https://mowatcentre.ca/wpcontent/uploads/publications/153 delivering benefit.pdf 